\title{
Assessment of job satisfaction among hospital pharmacists in Saudi Arabia
}

\author{
Bander Balkhi ${ }^{1}$, Ahmad Alghamdi ${ }^{1}$,Nasser Alshehri ${ }^{2}$, Abdulrahman Alshehri ${ }^{3}$ \\ 1. College of Pharmacy, King Saud University, Riyadh, Saudi Arabia. \\ 2. Riyadh Military Hospital, Riyadh, Saudi Arabia. \\ 3. MCPHS University, Boston, MA, USA
}

\begin{abstract}
Background: Job dissatisfaction at work has been associated with low productivity, absenteeism, high turnover, and workers reducing their hours. Little is known about job satisfaction among pharmacists in Saudi Arabia and why they are leaving their profession. This study aims to assess job satisfaction status among Saudi pharmacists working in different practice sites in Saudi Arabia and to explore factors associated with job satisfaction among pharmacists in Saudi Arabia.
\end{abstract}

Method: A cross-sectional questionnaire survey of pharmacists working in government and private hospitals in Saudi Arabia.

Results: A total of 122 pharmacists answered the survey, of which $42.98 \%$ were satisfied with the size of their work place and stated it was large enough to perform their job, and $47.11 \%$ were satisfied regarding having access to computer resources such as Internet and pharmaceutical references. The main factors for job satisfaction were salary, workload, work environment, training and education opportunities, promotion, and incentives.

Conclusion: Job satisfaction among pharmacists is relatively low and may create economic and work force complications in Saudi Arabia. Education, training, and promotions within each premises as well as policies concerning general classification and ranking systems need to be re-evaluated to improve overall job satisfaction.

Keywords: Job satisfaction; Dissatisfaction; Pharmacists; Saudi Arabia; Cross-sectional

\section{INTRODUCTION}

Job satisfaction is a very important issue because it has many professional and economic implications. Individual job dissatisfaction has always been associated with poor mental health, in particular with stress and anxiety $[1,2]$. On the organizational level, job dissatisfaction at work has been associated with low productivity, low organization effectiveness, absenteeism, high turnover, and workers reducing their hours and withdrawing from the labor market [3,4]. Many studies in the literature have tackled the area of job satisfaction among various professions $[5,6]$. Theories suggested include assuming a bi-dimensional model for factors affecting job satisfaction such as "intrinsic" and "extrinsic" satisfaction dimensions [7] or, alternatively, "satisfaction/lack of satisfaction" and "dissatisfaction/lack of dissatisfaction" dimensions [8]. There is always a debate about whether job satisfaction is a global "overall" measure, or if it is composed of many facets of different aspects of each individual $[9,10]$. The most determinant factors for job satisfaction have been recognized as job interestingness, relationships with managers and colleagues, high income, and clearly defined career advancement opportunities [11].

A number of instruments and questionnaires have been utilized by many investigators to assess the level of job satisfaction. These include the Warr Job Satisfaction Questionnaire, the Occupational Stress Indicator, the Michigan Organizational Assessment Questionnaire, the Job Diagnostic Survey, the Job Descriptive Index "work itself" subscale, the Minnesota Satisfaction Questionnaire, and theBrayfield-Rothe Questionnaire [2]. All of these tools are self-report multi-item questionnaires that investigate some characteristics of the work place and environment as well as the staff and incentives. Some studies explored the reasons why pharmacists tend to quit their jobs. In Australia, lack of career paths and opportunities, underutilization of pharmacists' knowledge and skills, and the desire for change are among the most common factors that lead to dissatisfaction [12].

Other works tried to understand the turn-over in hospital pharmacists jobs in the Chicago area and found that the pharmacists' salaries, benefits, and promotions were the reasons pharmacists ranked as most 
important for leaving and staying at a job [13]. In that study, salary and benefits were the most important reasons mentioned by men while hospital location was the most important reason for satisfaction by women. Other factors were considered important, including hours, professional challenge, job duties, and continuation of education. Management could also have a great impact on the level of job satisfaction by employees. Additionally, bad perception of the management and administration by employee pharmacists in both hospital and community settings resulted in increased levels of job dissatisfaction and may lead to increasing the rate of job turnover [14].

Pharmacists' knowledge about the job, number of clinical services performed, and the actual amount of time spent by the pharmacist providing these activities are other important factors that increase the level of job satisfaction among hospital pharmacists [12,15]. Autonomy was named as one of the most common causes besides workload, work control, and management style for stressors that may lead to job dissatisfaction [13].

There is a gap in the literature about the level of job satisfaction among pharmacists in Saudi Arabia and the factors behind it. Only one study has been published so far that investigated the level of pharmacist job satisfaction in Saudi Arabia, and their target was non-Saudi pharmacists working in community settings only $[16,17]$. The aim of this study is to assess job satisfaction status among Saudi pharmacists working in different practice sites of Saudi Arabia and also to explore factors associated with job satisfaction among pharmacists in Saudi Arabia.

\section{MATERIAL AND METHODS}

A cross-sectional online questionnaire was conducted from June 2015 to September 2015 to measure job satisfaction among pharmacists in Saudi Arabia. A web-based questionnaire was developed and distributed online through the SurveyMonkey website. The survey consisted of 11 questions about pharmacists' demographics and 33 closed-ended questions about job satisfaction and factors associated with it. The survey was adapted from a survey conducted and validated by the American Society of Health-System Pharmacists (ASHP) about pharmacists' job satisfaction in the USA [18].

Before the survey was implemented, it was validated by a group of 6 experts for face and content validity. Then, it was pilot-tested on a sample of 15 Saudi pharmacists to assess and validate the clarity and understandability of the survey questions, which resulted in the need for minor modifications. Several measurements of job satisfaction were considered and included based on an in-depth review of the literature. These factors were categorized as follows: work environment, education and training, salaries, management, pharmacist patient relationship, the professional encounter - co-workers, work schedule, work environment, rewards, and overall job satisfaction. Survey questions in all of these categories were given a 5-point scale (strongly agree, agree, not applicable, disagree, and strongly disagree). All the questions were adjusted to fit the different working settings of the participants. Demographic characteristics of participants were included in the survey such as age, gender, region of residence, marital status, degree of education, working site, monthly salary, job title, and years of experience.

Our target population was Saudi pharmacists working in different settings. Pharmacists working at the Ministry of Health and public or private hospitals' pharmacies with, at a minimum, a Bachelor's degree in Pharmaceutical Sciences were eligible to be included in this study. The sampling strategy used in the study was snowball sampling, starting with contacting the Saudi Pharmaceutical Society and using a personal e-mail message explaining the objective of the survey and describing the targeted population. The message included a direct link to the survey to be further distributed by the society to pharmacists who were eligible to participate according to the descriptions in the e-mail.

\section{RESULTS}

Of the pharmacists surveyed, 133 pharmacists answered the survey; the response rate was $72 \%$. 11 respondents were not included in the analysis because of missing data, resulting of a total of 122 respondents included in this study. Table 1 displays the demographic variables of pharmacists participating in this study. A total of $72 \%$ of respondents were male and 59\% were 26-30 years old. More than half of respondents were married (68\%) and the majority worked in the central region of Saudi Arabia. Sixty-four percent of respondents reported that their highest degree was the Bachelor of Science. Thirty-five percent of respondents worked in a military hospital, $28 \%$ in university hospitals, and $25 \%$ in government hospitals. Forty-five percent of pharmacists surveyed reported that they had less than 5 years of experience. Almost half of the respondents were pharmacists, $15 \%$ were supervisors, and $10 \%$ were clinical pharmacists. A significantly higher proportion of respondents indicated that their salary ranged from 10,000-20,000 Saudi Riyals.Forty-three percent of respondents were satisfied with the size of their work place to perform their job. Almost half of respondents were satisfied with the accessibility they had to computer resources like Internet and pharmaceutical references. The majority of the respondents were satisfied with the availability of the necessary equipment required to perform their job. 
Table 1. Demographic characteristics of respondents $(n=122)$

\begin{tabular}{|c|c|}
\hline 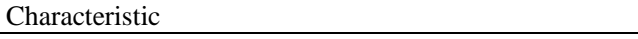 & \\
\hline Sex & Respondents $n(\%)$ \\
\hline Female & $34(28)$ \\
\hline Male & $86(72)$ \\
\hline \multicolumn{2}{|l|}{ Age(years) } \\
\hline Less than 25 & $6(5)$ \\
\hline $26-30$ & $71(59)$ \\
\hline $31-35$ & $26(22)$ \\
\hline $35-40$ & $11(9)$ \\
\hline $41-45$ & $3(3)$ \\
\hline Over & $3(3)$ \\
\hline \multicolumn{2}{|l|}{ Marital status } \\
\hline Married & $81(68)$ \\
\hline Single & $39(33)$ \\
\hline \multicolumn{2}{|l|}{ Practice site } \\
\hline Government hospitals & $30(25)$ \\
\hline Private hospitals & $7(6)$ \\
\hline University hospitals & $34(28)$ \\
\hline Military hospitals & $42(35)$ \\
\hline Specialty hospitals and treatment centers & $6(5)$ \\
\hline \multicolumn{2}{|l|}{ Regions } \\
\hline North & $2(2)$ \\
\hline South & $10(8)$ \\
\hline Central & $89(74)$ \\
\hline West & $15(12)$ \\
\hline East & $5(4)$ \\
\hline \multicolumn{2}{|l|}{ Employment status } \\
\hline Government & $67(57)$ \\
\hline Subcontracted & $33(28)$ \\
\hline Military & $18(15)$ \\
\hline \multicolumn{2}{|l|}{ Years in practice } \\
\hline Less than 5 & $54(45)$ \\
\hline $5-10$ & $47(39)$ \\
\hline $11-15$ & $12(10)$ \\
\hline $16-20$ & $7(6)$ \\
\hline More than 20 & $1(1)$ \\
\hline \multicolumn{2}{|l|}{ Job title } \\
\hline Pharmacist & $61(50)$ \\
\hline Clinical pharmacist & $12(10)$ \\
\hline Senior pharmacist & $17(14)$ \\
\hline Supervisor & $18(15)$ \\
\hline Director & $4(3)$ \\
\hline Others & $9(7)$ \\
\hline \multicolumn{2}{|l|}{ Saudi Commission for Health Specialties' classification } \\
\hline Pharmacist & $75(63)$ \\
\hline Pharmacist 1 & $32(27)$ \\
\hline Consultant pharmacist 3 & $3(3)$ \\
\hline Not classified yet & $9(8)$ \\
\hline \multicolumn{2}{|l|}{ Highest degree } \\
\hline Bachelor of Science (BS) & $77(64)$ \\
\hline Doctor of Pharmacy (Pharm.D.) & $16(13)$ \\
\hline Master of Science (MS) & $25(21)$ \\
\hline Ph.D. & $2(2)$ \\
\hline \multicolumn{2}{|l|}{ Monthly salary } \\
\hline Less than 10,000 & $4(3)$ \\
\hline $10,000-15,000$ & $47(39)$ \\
\hline $15,000-20,000$ & $45(37)$ \\
\hline $20,000-25,000$ & $18(15)$ \\
\hline $25,000-30,000$ & $3(3)$ \\
\hline More than 30,000 & $4(3)$ \\
\hline
\end{tabular}

In regards to education and training, over half of respondents were not satisfied with the education and training they received and they did not get fair opportunities to continue their education (Table 2). The majority of respondents demonstrated dissatisfaction with their salaries, income, and incentives. More than half of the participants disagreed with the incentives they got and stated that their salaries were less than the salaries of other pharmacists holding similar positions in other practices. Most of the participants were not satisfied with the new salary scale (the system used for all medical job ranking).Only $37 \%$ of respondents agreed that their 
supervisors gave enough consideration to their complaints. Almost $60 \%$ demonstrated having a good relationship with their supervisors. When the participants were asked if their departments gave clear policy about promotions, 56\% disagreed. Less than half of respondents were satisfied with their relationship with coworkers and staff from other departments. Over half of the respondents reported good communication with the staff from other departments about job related matters. In contrast, only $37.61 \%$ of respondents felt that society did not afford them with the status they deserved. Almost 35\% of respondents indicated that individual employee needs and preferences were taken into account when work hours were scheduled.

Table 2. Satisfaction level among Saudi phamacists

\begin{tabular}{|c|c|c|}
\hline Question & Satisfied \% & Unsatisfied \% \\
\hline The size of my work place is sufficient to perform my duties & 42.9 & 57.1 \\
\hline The physical arrangement of my practice setting facilitates the quality of work & 44.3 & 55.7 \\
\hline The physical arrangement of my practice setting facilitates workflow & 46.0 & 54.0 \\
\hline Ihave access to computer resources (e.g., intemet, medical and pharmaceutical references) & 49.0 & 51.0 \\
\hline I have access to necessary equipment and technologies required to perform my job duties & 68.0 & 32.0 \\
\hline The hired staff have received enough training to perform their job duties & 42.0 & 58.0 \\
\hline My salary is equivalent to the salaries of persons holding similar positions in other practice sites & 52.0 & 48.0 \\
\hline I am satisfied with the new salary scale set by the MOH for the phamacy profession & 32.0 & 68.0 \\
\hline My supervisor gives enough consideration to my complaints & 37.0 & 63.0 \\
\hline I have a good relationship with my supervisor & 63.0 & 37.0 \\
\hline My supervisor has adequate knowledge of his/her job & 55.0 & 45.0 \\
\hline My supervisor is decisive when a situation calls for a decision & 49.0 & 51.0 \\
\hline My department gives clear policy about promotions & 44.0 & 56.0 \\
\hline My employer hires only highly competent people & 61.0 & 39.0 \\
\hline My department has clear, stable, and doable policies and procedures & 72.0 & 28.0 \\
\hline Clients show appreciation for the services I provide for them & 43.0 & 57.0 \\
\hline My fellow co-workers treat me with the respect I deserve & 55.0 & 45.0 \\
\hline Staffs from other departments are cooperative when I initiate communication with them about job-related matters & 57.0 & 43.0 \\
\hline Considering the amount of education which pharmacists have, the society accords them the status they deserve & 64.0 & 36.0 \\
\hline Individual employee needs and preferences are taken into account when work hours are scheduled & 38.0 & 62.0 \\
\hline Management is fair in scheduling overtime, evenings, nightshifts, weekends, and holiday hours & 41.0 & 59.0 \\
\hline My work schedule gives me enough time for my personal life & 39.0 & 61.0 \\
\hline My workload is reasonable & 34.0 & 66.0 \\
\hline During the work hours of the shift, there is enough staff to cover the workload & 31.0 & 69.0 \\
\hline All things considered I am satisfied with my current job & 47.0 & 53.0 \\
\hline I consider spending the remainder of my career in my current job & 34.0 & 66.0 \\
\hline I often leave work with a "bad" feeling, a feeling that I am doing something which I do not enjoy & 38.0 & 62.0 \\
\hline
\end{tabular}

Pharmacists working in private hospitals indicated the highest degree of satisfaction regarding the work schedule. Clinical pharmacists were among the highest who complained about the workload. A significantly higher proportion of females (40\%) compared to males (30\%) did not agree with the work schedule and they demonstrated that they did not have enough time for their personal lives. Although $47 \%$ of pharmacists were satisfied with their current job, only $34 \%$ of them considered spending the remainder of their career in their current job. Additionally, the main factors for job dissatisfaction were low salary (66\%), high workload (65\%), work schedule $(61 \%)$, training and education opportunities (62\%), promotion opportunities (62\%), and lack of incentive (54\%)|(Table 3).Not surprisingly, our survey found that pharmacists with a higher job title had higher job satisfaction compared to others. Additionally, we found that pharmacists with a higher academic degree had higher job satisfaction than other pharmacists. A high proportion of males $(47 \%)$ reported a higher rate of satisfaction compared to females (30\%). Pharmacists working at specialty hospitals showed higher satisfaction than other pharmacists. Directors were at the top level of satisfaction followed by clinical pharmacists. Significantly, more years of experience were accompanied by a higher satisfaction level.

Table 3. Factors affecting satisfaction level

\begin{tabular}{|l|l|}
\hline Factors & Agree $n(\%)$ \\
\hline Work environment & $72(59)$ \\
\hline Incentive & $66(54)$ \\
\hline Promotion & $78(64)$ \\
\hline Work load & $79(65)$ \\
\hline Work schedule & $74(61)$ \\
\hline Relationship with co-workers & $55(45)$ \\
\hline Salary & $81(66)$ \\
\hline Training and education opportunities & $75(62)$ \\
\hline
\end{tabular}




\section{DISCUSSION}

This study was conducted to assess the status of job satisfaction among pharmacists in the country of Saudi Arabia. Overall, less than $50 \%$ of responding pharmacists were satisfied with their job. This level is lower than what has been reported in the literature [19-21]. The majority of satisfied pharmacists were from military hospitals because they offer good chances for training, scholarships, and getting exposed to various tasks. These characteristics make military hospitals more desirable destinations for freshly graduated students than other smaller hospitals. The majority of respondents were not satisfied with the new salary scale because it includes the classification of pharmacists based on their qualifications, which disregards the pharmacist's experience and focuses only on certificates, which leaves pharmacists with longer years of experience not satisfied because they believe they deserve more. Pharmacist income in Saudi Arabia mostly consists of a monthly salary (fixed amount). Incentives are given according to the department's policy and could be in the form of financial or nonfinancial (e.g., days off) compensation. Some departments are deprived of that privilege because it is usually under the governance of hospital-wide policies to prevent possible chances for corruption. The majority of respondents in our sample believed that they were not offered a fair chance for incentives. The high level of disagreement regarding the education and training that was described by our respondents $(50.4 \%$ and $52.1 \%$ for training and education, respectively) necessitate quick policy changes. Although our sample is not representative of all pharmacists in Saudi Arabia, we believe that if there were such a problem in the central region, then this problem could be worse in other regions.

Good relations with managers and supervisors were reflected by our respondents reporting high percentages of them agreeing that their managers or supervisors were decisive, had good relationships with them, and had an adequateknowledge about their jobs. This area remains grey concerning whether their supervisors gave enough considerations to their complaints. The only possible explanation to that is the individual variation that might exist from one pharmacist to the other and the uniqueness of each case. Satisfaction rate with the promotions policy is not that great, suggesting that this area needs better attention from the administration since the absence of clear policy might lead to high quitting and turnover rates [22]. There was a high rate of satisfaction with the clarity of policy and procedures in general, and this result is expected since quality assurance practices in any hospital require that all departments, including the pharmacy department, have clear policies and procedures that go through the approval of several committees. It is one of the employees' rights to ask for these policies and procedures before they even start taking actual duties and make sure that they understand them very well and also ask questions if they feel something is not clear about them.

The scheduling of hours in the pharmacy did not meet the satisfaction of the majority of the respondents, and there are a number of good explanations for this. The fixed schedule of some pharmacies may not be suitable for all pharmacists; and the work schedule of a lot of pharmacies include evening shifts, night shifts, and weekends in addition to working during holidays and summertime, which are all not popular choices to many people and could create strain for some pharmacists who would want to be spared from these time schedules. However, in the end, these time schedules need to be filled by someone to keep the pharmacy working.

Clinical pharmacists complained about the workload the most. This could be because of the fact that there is almost always one clinical pharmacist assigned to one specialty in a hospital (e.g., cardiology, medicine, pediatrics), and the clinical pharmacist covering this area is likely the pharmacy representative. Therefore, he/she is required to handle most of the clinical and non-clinical responsibilities and is sometimes kept on call after working hours to respond to any cases of emergencies. This plethora of responsibilities make clinical pharmacists feel that they are burdened with all these responsibilities and they need assistance by having more than one pharmacist/clinical pharmacist assigned to the same specialty, and we think that is what makes most of them complain about workload. A higher percentage of female pharmacists were not satisfied with the work hours and not having enough time for their personal lives. This could be because of the fact that working in a pharmacy requires an 8-hour shift that, compared to other jobs, may be perceived as extended hours of work.

Overall global satisfaction was considered low and the decision to remain in the same career was even lower, which is really an alert that may lead to high turnover rates and withdrawal from the labor market. The trend that we see in the responses about global job satisfaction is as follows: the higher the position, job title, education level, prestigiousness of the place, and years of experience, the higher the level of overall job satisfaction. These findings were consistent with earlier findings that satisfaction levels varied according to the practice setting and job title due to differences in the clinical activities and work environment within the practice settings [22,23]. 
Our finding indicated that directors reported the highest satisfaction scores as compared to other segments of our sample. This makes sense because people in general strive to be perceived as better persons and that rule holds true for any health profession. Male pharmacists overall reported higher levels of global job satisfaction as compared to females.

\subsection{Limitations}

The sample was small and not indicative of all the possible trends of the pharmacy practice in Saudi Arabia because the majority of the sample was from the central region. Other possible trends that we did not draw from this small sample could be out there. Most of the respondents were fresh graduates with less than 5 years of experience, which might not be representative of the majority of pharmacists in Saudi Arabia. However, this represents the age group that is more interested in participation in general activities and more eager for cooperation. The sampling technique used in this study (snowball sampling) could result in some bias in answering some of the questions.

\section{CONCLUSIONS}

Our findings suggest that policies governing the pharmacy profession need to be addressed with more concern as the level of job satisfaction, based on our findings, is relatively low and may create economic and work force complications in Saudi Arabia. Most of the things that need to be reevaluated are the policies governing education, training, and promotions within each premise as well as policies concerning general classification and ranking systems. This work needs to be further validated by including a larger representative sample of pharmacists from different practice sites and all regions so that an appropriate intervention can be conducted to improve the profession's status.

\section{Funding}

This research did not receive any specific grant from funding agencies in the public, commercial, or not-forprofit sectors.

\section{REFERENCES}

[1] Cooper, C.L., Rout, U., Faragher, B., 1989. Mental health, job satisfaction, and job stress among general practitioners. BMJ 298, 366-70.

[2] Faragher, E.B., Cass, M., Cooper, C.L., 2005. The relationship between job satisfaction and health: a meta-analysis. Occup. Environ. Med. 62, 105-12.

[3] Clegg, C.W., 1993. Psychology of employee lateness, absence and turnover. J. Appl. Psychol. 68, 88101.

[4] Freeman, R.B., 1978. Job satisfaction as an economic variable. Am. Econ. Rev. 93, 135-41.

[5] Lichenstein, R.L., 1998. The job satisfaction and retention of physicians in organized settings: a literature review. Med. Care 41, 139-179.

[6] Mein, G., Martikainen, P., Stanseld, S.E., Brunner, E.J., Fuhrer, R., Marmot, M.G., 2000. Predictors of early retirement in British civil servants. Age Ageing 29, 529-536.

[7] Warr, P., Cook, J., Wall, T., 1979. Scales for the measurement of some work attitudes and aspects of psychological well-being. J. Occup. Psychol. 52, 129-148.

[8] Winefield, A.H., Tiggemann, M., Goldney, R.D., 1988. Psychological concomitants of satisfactory employment and unemployment in young people. Soc. Psychiatry Psychiatr. Epidemiol. 23, 149-157.

[9] Oshagbemi, T., 1999. Overall job satisfaction: how good are single vs. multiple-item measures? J. Manag. Psychol. 14, 388-403.

[10] Wanous, J.P., Reichers, A.E., Hudy, M.J., 1997. Overall job satisfaction: how good are single item measures? J. Appl. Psychol. 82, 247-252.

[11] Sousa-Poza A, Sousa-Poza A.A., 2000. Well-being at work: a cross-sectional study of the levels and determinants of job satisfaction. J. Socio. Econ.29, 517-38.

[12] Mak, V.S., March, G.J., Clark, A., Gilbert, A. L., 2013. Why do Australian registered pharmacists leave the profession? A qualitative study. Int. J. Clin. Pharm. 3, 129-137.

[13] Smith, S.N., Stewart, J.E., Grussing, P.G., 1986. Factors influencing the rate of job turnover among hospital pharmacists. Am. J. Health Syst. Pharm. 43, 1936-1941.

[14] Ferguson, J., Ashcroft, D., Hassell, K., 2011. Qualitative insights into job satisfaction and dissatisfaction with management among community and hospital pharmacists. Res. Social Adm. Pharm.7, 306-316.

[15] Olson, D.S., Lawson, K.A., 1996. Relationship between hospital pharmacists' job satisfaction and involvement in clinical activities. Am. J. Health Syst. Pharm. 53, 281-284.

[16] Bawazir, S.A., 2005. Job satisfactions in Saudi community pharmacists. JPPR. 25, 334. 
[17] Suleiman, A.K., 2015. Stress and job satisfaction among pharmacists in Riyadh, Saudi Arabia. Saudi J. Med. Med. Sci. 3, 213.

[18] ASHP Document Library, 2015. American Society of Health System Pharmacists Website. Accessed 12.03.2016

[19] Kerschen, A.M., Armstrong, E.P., Hillman, T.N., 2006. Job satisfaction among staff, clinical, and integrated hospital pharmacists. J. Pharm. Prac. 19, 306-312.

[20] Maio, V., Goldfarb, N.I., Hartmann, C.W., 2004. Pharmacists' job satisfaction: variation by practice setting.PharmTher 29, 184-190

[21] McCann, L., Hughes, C.M., Adair, C.G., Cardwell, C.,2009. Assessing job satisfaction and stress among pharmacists in Northern Ireland. Pharm. World Sci. 31, 188.

[22] Seston, E., Hassell, K., Ferguson, J., Hann, M., 2009. Exploring the relationship between pharmacists' job satisfaction, intention to quit the profession, and actual quitting. Res. Social Adm. Pharm. 5, 121-132.

[23] Lau, W.M., Pang, J., Chui, W., 2011. Job satisfaction and the association with involvement in clinical activities among hospital pharmacists in Hong Kong. Int. J. Pharm. Prac. 19, 253-263. 